\title{
Polymers of a transition-state sialyl cation strongly inhibit bacterial sialidases.
}

\author{
Coralie Assailly, ${ }^{[a]}$ Clarisse Bridot, ${ }^{[b]}$ Amélie Saumonneau, ${ }^{[c]}$ Paul Lottin, ${ }^{[d]}$ Benoit Roubinet, ${ }^{[e]}$ Eva-Maria \\ Krammer, ${ }^{[b]}$ Francesca François, ${ }^{[\mathrm{d}]}$ Frederica Vena, ${ }^{[\mathrm{e}]}$ Ludovic Landemarre, ${ }^{[\mathrm{e}]}$ Dimitri Alvarez Dorta, ${ }^{[\mathrm{a}]}$ \\ David Deniaud, ${ }^{[a]}$ Cyrille Grandjean, ${ }^{[c]}$ Charles Tellier, ${ }^{[c]}$ Sagrario Pascual, ${ }^{[d]}$ Véronique Montembault, ${ }^{[d]}$ \\ Laurent Fontaine, ${ }^{[d]}$ Franck Daligault, ${ }^{[c]}$ Julie Bouckaert, ${ }^{[b]}$ Sébastien G. Gouin ${ }^{*[a]}$
}

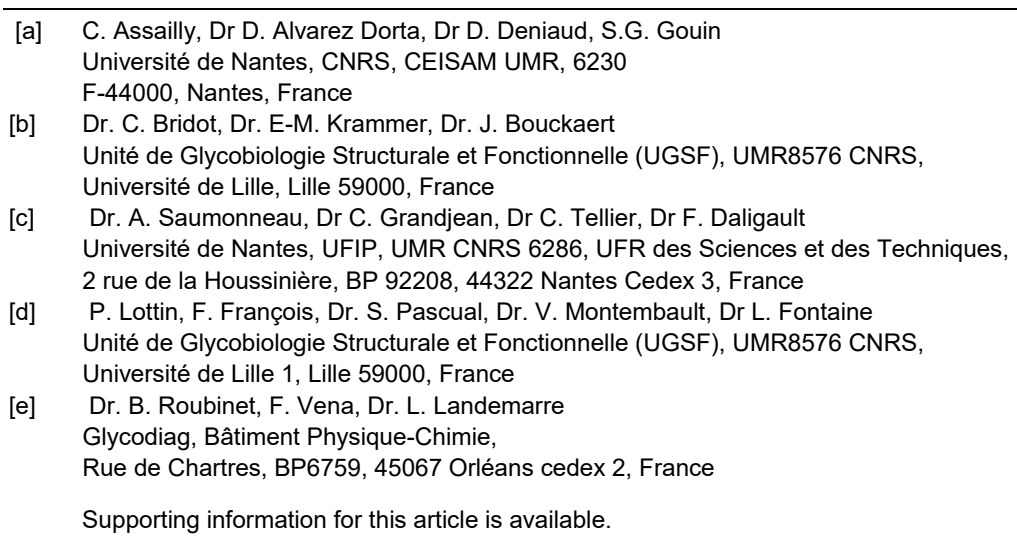

\begin{abstract}
Bacterial sialidases (SA) are validated drug targets expressed by common human pathogens such as Streptococcus pneumoniae, Vibrio cholerae or Clostridium perfringens. Noncovalent inhibitors of bacterial SA capable of reaching the submicromolar level are rarely reported. We developed multi- and polyvalent compounds based on the transition state sialyl cation 2deoxy-2,3-didehydro- $N$-acetylneuraminic (DANA). Poly-DANA inhibits the catalytic activity of SA from $S$. pneumoniae (NanA) and the symbiotic microorganism $B$. thetaiotaomicron (BtSA) at the picomolar and low nanomolar levels when expressed in moles of molecules and of DANA, respectively. Each DANA grafted to the polymer surpasses the inhibitory potential of the monovalent analogue by more than four orders of magnitude, which represents the highest multivalent effect reported so far for an enzyme inhibition. The synergistic interaction was shown to operate exclusively in the catalytic domain, offering interesting perspectives for the multivalent inhibition of other SA families lacking such as a carbohydrate-binding domain, such as viral, parasitic or human SA.
\end{abstract}

\section{Introduction}

Sialidases (SA) are a family of exoglycosidases hydrolysing sialic acid, a negatively charged a-keto monosaccharide with nine carbon backbone atoms displayed at the outermost end of glycans, glycoproteins or glycolipids. SA are widely present in animal species, and unbalanced human SA activity plays a crucial role in diabetes, inflammation, cancers and cardiovascular and lysosomal storage diseases. [1] SA are also common virulent factors of pathogenic microorganisms, enabling them to develop biofilms, to feed on host sialic acid, or to infect cells by unmasking binding ligands. SA are therefore particularly relevant targets for the development of anti-infective therapies against viruses, bacteria, fungi and parasites. Considering the rapid development of antimicrobial resistance to prescribed antibiotics or antifungals, there is an urgent need to develop therapeutic approaches targeting such new virulent factors. Active research in this domain was rewarded by the approval of anti-influenza drugs such as oseltamivir (Tamiflu) and zanamivir (Relenza) blocking viral SA and preventing virion release and spread from the infected cells. There has been less success with bacterial, fungal or parasitic SAs, and there are few reports of inhibitory activities for bacterial $\mathrm{SA}$ in the nanomolar range. ${ }^{[2,3]}$ The most promising inhibitors of bacterial and human SA (NEU1-4) ${ }^{[4]}$ are based on 2-deoxy-2,3didehydro-N-acetylneuraminic (DANA), a transition-state analogue of the sialyl cation after SA cleavage (Figure 1A). DANA modifications with adequate pharmacophores at the C-5 or C-9 positions were shown to improve affinity and selectivity for specific hNEU isoenzymes. ${ }^{[1,4-8]}$ The group of Chen developed triazolelinked peptide in C-9 position of DANA with micromolar and selective inhibition of $V$. cholerae SA. ${ }^{\left[{ }^{9]}\right.}$

Virulent factors interfering with host sialoglycans may also be efficiently targeted or inhibited with synthetic glycoclusters bearing several copies of the sialic acid epitope. These multivalent inhibitors proved particularly effective for lowering the binding ability of human adenovirus or influenza virus strains, by blocking trimeric sialic acid binding proteins at the surface of the viral capsides. ${ }^{[10-14]}$ The viral neuraminidase, a homotetrameric enzyme allowing virions release from cell surfaces after sialic acid cleavages, was also efficiently inhibited by the same approach. Oligo- and poly-mers of the drug zanamivir (ZV), showed impressive in vivo protection of infected mice, higher than the parent ZV. ${ }^{[15-17]}$ Polymeric ZV are however not suited for bacterial $S A$ inhibition. First $S A$ catalytic domains do not arrange in multimers at the bacterial surface, and second the ZV ligand displays only a weak binding affinity for these enzymes due to different active site architectures. ${ }^{[18]}$

Bacterial SAs from the GH33 family share a six-bladed $\beta$-propeller catalytic domain (CAT), often flanked with a lectinic domain or carbohydrate-binding module (CBM). The role of these CBM is not clearly understood, but they were proposed to significantly improve the enzymatic catalytic efficiency for polysialylated 
surfaces. ${ }^{[19]}$ Inspired by these results, we recently designed nonhydrolysable polyvalent thiosialosides to bind to the CAT and CBM domains simultaneously. These sialoclusters displayed submicromolar binding inhibition capacity and inhibitory activity for the pathogenic SA from Vibrio cholerae (VcSA) and Streptococus pneumoniae (NanA). ${ }^{20]}$ Each clustered thiosialoside showed enhanced inhibitory capacity up to three orders of magnitude compared with relevant monovalent references.

Surprisingly, these synergistic inhibitory effects were also observed for NanA catalytic domains alone (CAT), truncated from CBM. More potent CAT binder than the millimolar affinity thiosialosides may therefore provide higher levels of inhibition. These results also suggested that CAT domains of SA are sensitive to multivalent inhibitory effects as previously shown with multivalent iminosugars and specific glycosidases. ${ }^{[21-24]}$ In this work, we select the DANA ligand to develop the first class of multiand polyvalent sialyl cation transition-state inhibitors of bacterial SA (Figure 1B). The DANA-clusters inhibition potentials were assessed towards SA from Bacterioides thetaiotaomicron (BtSA), and Streptococcus pneumoniae (NanA) both belonging to the GH33 family These enzymes were produced both in their full length (CAT+CBM) and as CAT domains alone (for NanA).
The SA from B. thetaiotaomicron, a symbiotic commensal microbe of the intestinal tract, has a unique CBM at the $N$-terminal end of the CAT that, shares low sequence similarity (6 to 10\%) to other CBM present in the CAZY database. A specificity of this SA is that the CAT and CBM domains are very close to each other $(17 \AA)$ compared with the same two SA domains of other pathogenic bacteria. ${ }^{[25]}$ To date, little attention has been payed to the inhibition of SA from commensal bacteria despite their potential interest as an obesity-regulating target. ${ }^{[25]}$

$S$. pneumoniae remains a major cause of respiratory infections such as pneumonia, sinusitis or otitis, which can progress to forms of purulent meningitis. The S. pneumonia SA NanA, is expressed by $100 \%$ of strains and is an established virulence factor contributing to infection and virulence. ${ }^{[26]}$

Here, we designed synthetic DANA clusters with an unprecedented level of inhibitory capacity for GH 33 family SA enzymes. We studied the inhibitory capacity and binding interaction of the compounds on the full length BtSA and NanA and on the truncated NanA catalytic domain (NanA-CAT). Structural information on ligand binding was obtained from a NanA-CAT co-crystal structure, molecular dynamic simulation on DANA-NanA complexes and dynamic light scattering (DLS) experiments.

\section{A) Potent monovalent inhibitors based on DANA}

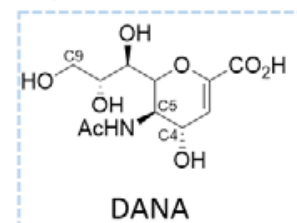

Bacterial SA $\left(K_{i} \sim \mu \mathrm{M}\right)$

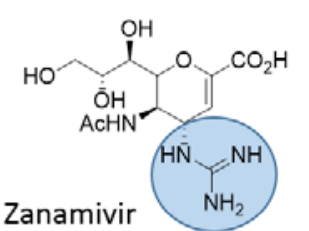

Viral SA $\left(K_{i}=10^{-8}-10^{-10} \mathrm{M}\right)$

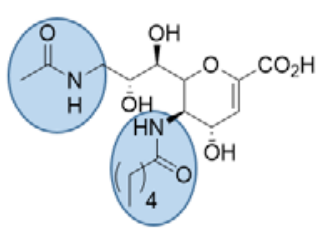

NEU1, $K_{i}=53 \mathrm{nM}$

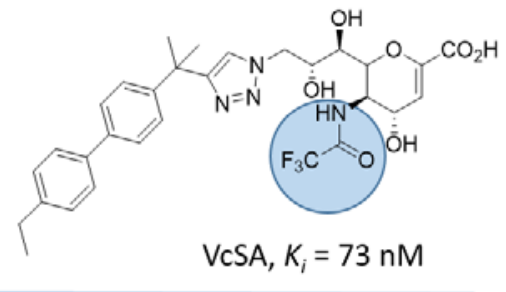

$\mathrm{VcSA}, K_{i}=73 \mathrm{nM}$

B) This work: DANA-clusters for the multivalent inhibition of bacterial sialidases

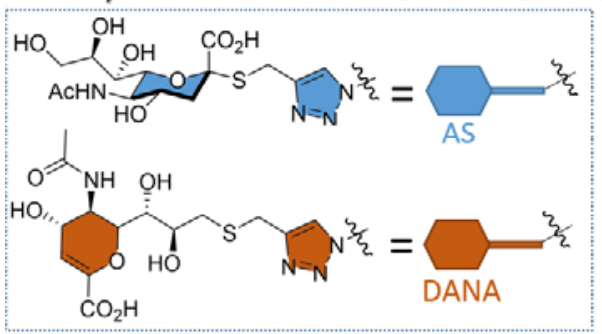

Monovalents

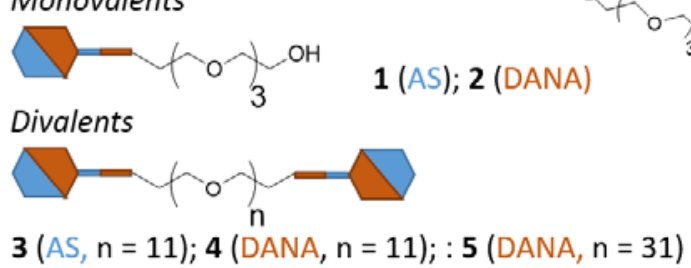

Hexavalents

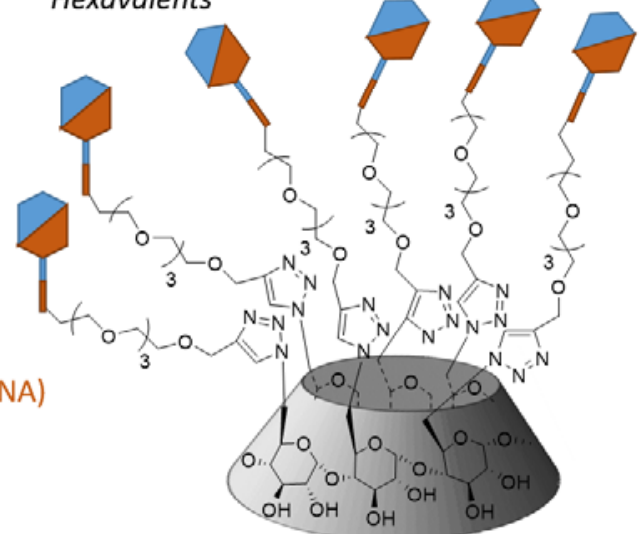

6 (AS); 7 (DANA)
Polyvalents (flexible cores)

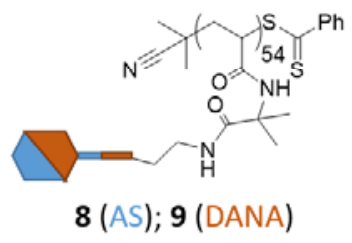

Polyvalent (rigid core)

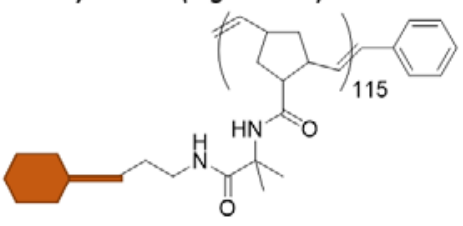

10 (DANA)

Figure 1. A) The most potent SA inhibitors previously reported were obtained by making structural modifications (shown in light blue) at C-4, C-5, and C-9 positions of DANA, a pan-inhibitor of bacterial SA with $K_{\mathrm{i}}$ in the $\mu \mathrm{M}$ range. These modifications were rewarded by the launch of zanamivir (Relenza $\left.{ }^{\circledR}\right),{ }^{[27]}$ an oral drug to treat influenza, and by the identification of potent and selective inhibitors of human neuraminidase (NEU1) ${ }^{[1]}$ and Vibrio cholerae sialidase (VcSA). ${ }^{[3]}$ B) In this work we propose an alternative strategy to potently inhibit bacterial SAs. DANA clusters were designed as multivalent transition-state inhibitors of bacterial SAs. The efficiency of the mono- and multivalent DANA derivatives 2, 4, 5, 7, 9 and 10 (in brown) was compared with mono- and multivalent analogues 1 , 3, 6, 8 bearing nonhydrolysable thiosialoside substrates (in blue). 


\section{Results and Discussion}

Previously described thiosialosides 1 and $3^{[20]}$ and new compounds $\mathbf{6}$ and $\mathbf{8}$ were first designed to compare the potential of the multivalent DANA with these substrate analogues.

Three types of DANA clusters were selected to provide potential multivalent inhibitory effects on bacterial SAs (Figure 1B). These compounds bear chemical groups attached to DANA structurally identical to the monovalent reference $\mathbf{1}$, which is necessary to calculate potential synergistic multivalent effects while excluding different binding signatures due to specific interactions in proximity to the binding site. The divalent DANA $\mathbf{4}$ and $\mathbf{5}$ with short and long spacer arm lengths, respectively, are potentially able to interact in the primary and a putative secondary binding site at the protein surface. Different levels of binding efficiency are expected depending on the spacer arm length. We previously estimated from polymer theory that the selected spacer arms for $\mathbf{4}$ and $\mathbf{5}$, bearing 10 and 30 PEG units, attain average distances of 22 and $33 \AA$, respectively. ${ }^{[20]}$ As previously observed with lectins, this value should match the distance between two protein binding sites for an optimal fit. ${ }^{[28]}$ The a-cyclodextrin (CD) scaffold of compound $\mathbf{7}$ was selected for a planar orientation of six DANA ligands. CD can be easily derivatized at the primary rim, a feature largely exploited for the design of glycoclusters. ${ }^{[29-31]}$ These size-controlled DANA-clusters were completed by two different types of DANA polymers $\mathbf{9}$ and $\mathbf{1 0}$ obtained by RAFT polymerization and ROMP, respectively. Glycopolymers designed for lectin inhibition have already been shown to provide large affinity enhancements for their targets due to their high density sugar contents, large distance spanning, and high adaptability. ${ }^{[32,33]}$ Members of this panel of compounds display unique topologies and architectures resulting from their different scaffolds. This structural diversity should cover the requirement for expected multivalent interaction through chelate, aggregative or statistical binding.

The synthesis was started by the chemical functionalization of DANA by an alkyne group, to subsequently graft the ligand on azido-armed EG, cyclodextrin or polymeric scaffolds by conventional copper-catalysed azide-alkyne cycloaddition (CuAAc). DANA was modified at C-9, a position previously shown to accept a wide range of chemical group (Figure 1A), and not buried in SA binding sites. ${ }^{[34]}$

First, we adapted previously described procedures for the fivestep synthesis of 11 (supp. mat). Briefly, protected $\mathrm{N}$-acetylneuraminic acid was chlorinated in the anomeric position with acetyl chloride, ${ }^{[35,36]}$ and treated with DBU to form the intracyclic double bond. Acetate deprotection of the hydroxyl groups was followed by selective C- 9 activation with $p$-toluene sulfonyl chloride in pyridine. Unstable compound $11^{[37]}$ was readily protected with acetates in pyridine to form 12 . The tosyl group was substituted with potassium thioacetate in DMF to give 13 with a moderate yield of $56 \%$. Diverse bases were envisaged for the selective thiol deprotection followed by an in situ alkylation with propargyl-bromide. The best reaction yields were obtained with an equimolar mixture of sodium methyl thiolate and potassium carbonate. After flash chromatography purification, $\mathbf{1 4}$ was deprotected with lithium hydroxide to form the expected compound 15 quantitatively.

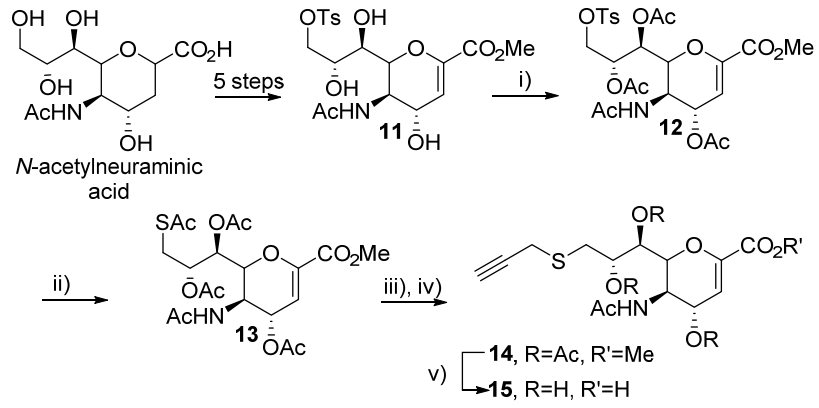

Scheme 1. Synthesis of alkynyl-DANA 10. i) $\mathrm{Ac}_{2} \mathrm{O}$, pyr, $0^{\circ} \mathrm{C} \rightarrow \mathrm{rt}, 1 \mathrm{~d}$, quant, ii) $\mathrm{KSAc}$, DMF, $60^{\circ} \mathrm{C}, 80 \mathrm{~min}, 56 \%$, iii) $\mathrm{NaSMe}, \mathrm{K}_{2} \mathrm{CO}_{3}, \mathrm{MeOH}, 0^{\circ} \mathrm{C}, 30 \mathrm{~min}$, then propargyl bromide, $0^{\circ} \mathrm{C} \rightarrow \mathrm{rt}$, $2 \mathrm{~h}$, workup, , evaporation, iv), pyr, $\mathrm{Ac}_{2} \mathrm{O}$, rt, $12 \mathrm{H} 90 \%$ over 3 steps, v) $\mathrm{LiOH}, \mathrm{MeOH}$, rt, $24 \mathrm{~h}$, quant.

The synthesis of mono-azido- $\mathrm{EG}_{3} 20$, di-azido- $\mathrm{EG}_{11,27} \mathbf{2 1 ,} 22$ and peracetylated azido- $\mathrm{EG}_{3}-\mathrm{CD} 23$ (Scheme 3) was described in previous articles. ${ }^{[29,31]}$ The two polyvalent azides 17 and 19 were obtained as depicted in Scheme 2. 2-Vinyl-4,4dimethyl-5-oxazolone (VDM) ${ }^{[38,39]}$ was polymerized by reversible addition-fragmentation chain transfer (RAFT) polymerization to form the poly(VDM $)_{54} \quad 16$ with $35 \%$ conversion (the conversion of the monomer was deliberately limited in order to access well-defined polymers ${ }^{[38,39]}$ ) after precipitation in hexane $\left(\overline{M_{n, N M R}}=7800 \mathrm{~g} \cdot \mathrm{mol}^{-1}, \overline{D P_{n, N M R}}=54\right.$, $\overline{M_{n, S E C}^{\text {THF }}}=8300 \mathrm{~g} \cdot \mathrm{mol}^{-1}$ and $\left.\boxminus=1.14\right)$. Polymer 18 was prepared by ring-opening metathesis polymerization (ROMP) of norbornenyl azlactone (NBAzl) using ruthenium-based Grubbs' third generation catalyst leading to a poly(NBAzl $)_{115}$ of $\overline{M_{n, N M R}}=23700 \mathrm{~g} \cdot \mathrm{mol}^{-1}, \overline{D P_{n, N M R}}=115, \overline{M_{n, S E C}^{T H F}}=25300 \mathrm{~g} \cdot \mathrm{mol}^{-1}$, $\bigoplus=1.12 .^{[40,41]}$ The azlactone moieties of polymers 16 and 18 were easily reacted with one equivalent of amine 12 to form the corresponding azido-polymers 17 and 19, respectively, as demonstrated by ${ }^{1} \mathrm{H}$ NMR spectroscopy and SEC analysis $\overline{\overline{\left(M_{n, S E C}^{T H F}\right.}}=16300 \mathrm{~g} \cdot \mathrm{mol}^{-1}, \Xi_{\mathrm{SEC}}=1.31$ and $\overline{M_{n, S E C}^{D M F}}=51100 \mathrm{~g} \cdot \mathrm{mol}^{-}$ $1, \oplus=1.16$ for 17 and 19 , respectively).

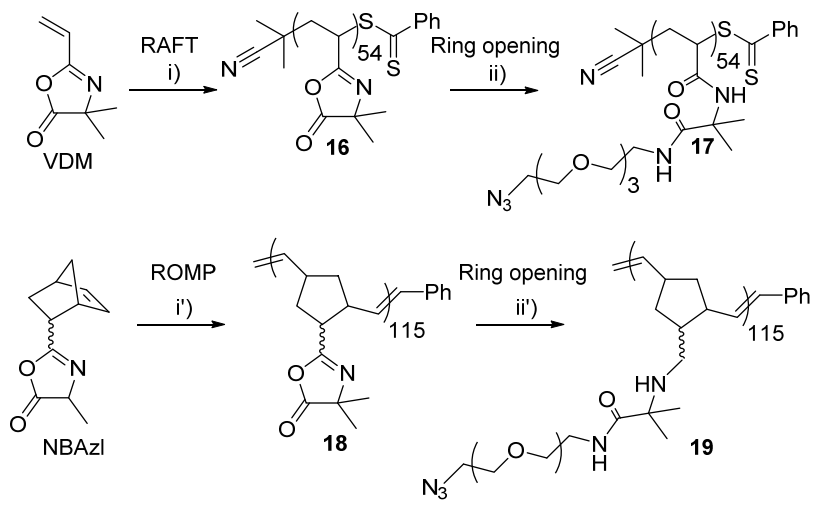

Scheme 2. Synthesis of azido-polymers 17 and 19 from VDM and NBAzI. i) 2-cyanoprop-2-ylbenzodithioate, AIBN $60^{\circ} \mathrm{C}$, 24h, 35\% ii) 11-Azido-3,6,9trioxaundecan-1-amine, THF, $40^{\circ} \mathrm{C}, 26 \mathrm{~h}$, quant.

The azido-functionalized scaffolds $\mathbf{2 0 - 2 3}$ and azido polymers 17, 19 were engaged in a copper-catalysed azide alkyne cycloaddition with acetyl-protected or unprotected DANA 
derivatives 14,15 , and thiosialoside 24 . Azide conversion was followed by $1 \mathrm{H}$ NMR and FT-IR and exclusive formation of the 1,4-triazole regioisomers $\mathbf{2 5 - 2 9}$ was demonstrated by the large $\Delta\left(\delta_{\mathrm{C}-4}-\delta_{\mathrm{C}-5}\right)$ values $(>20 \mathrm{ppm})$ observed using ${ }^{13} \mathrm{C}$ NMR. ${ }^{[42]}$

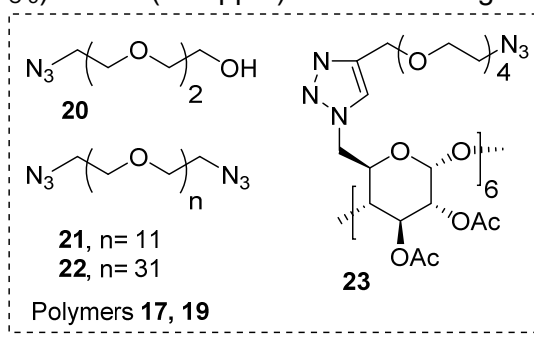

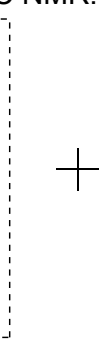

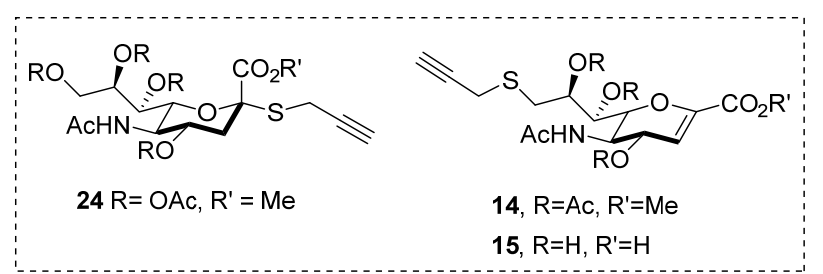

$$
\text { i) }
$$

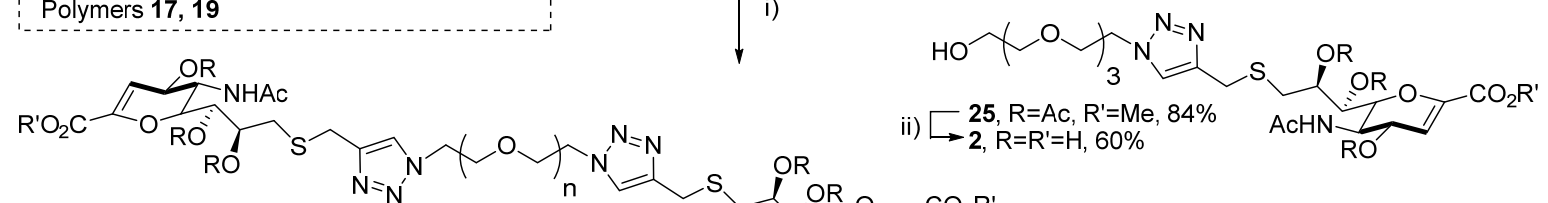

$$
\begin{aligned}
& \text { ii) 26, n=11, R=Ac, R'=Me, 55\% } \\
& \longrightarrow \text { 4, } n=11, \mathrm{R}=\mathrm{R}^{\prime}=\mathrm{H}, 60 \% \\
& \text { ii) 27, n=31, R=Ac, R'=Me, 55\% } \\
& \text { 5 }=31, R=R^{\prime}=H, 95 \%
\end{aligned}
$$

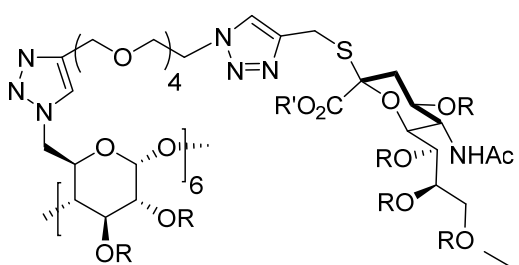

ii) $\longrightarrow$ 28, R=Ac, $R^{\prime}=M e, 48 \%$

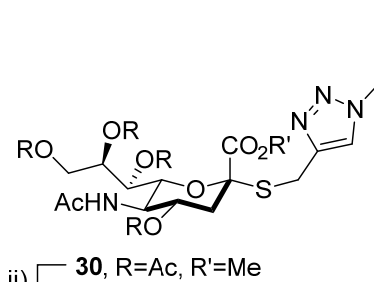

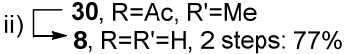<smiles>CCOCCNC</smiles>

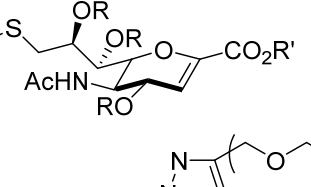

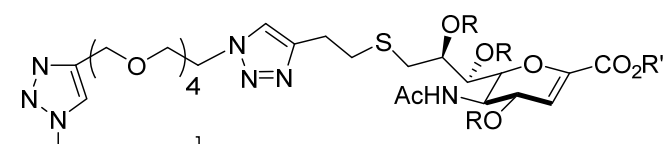<smiles>CCC1OC(O)C(O)C(O)C1C</smiles>

$\mathrm{OR}$

ii) $29, \mathrm{R}=\mathrm{Ac}, \mathrm{R}=\mathrm{Me}, 61 \%$

$\rightarrow 7, \mathrm{R}=\mathrm{R}^{\prime}=\mathrm{H}, 91 \%$<smiles>CC(C)(C#N)CC(SC(F)=S)C(N)=O</smiles>
Ph

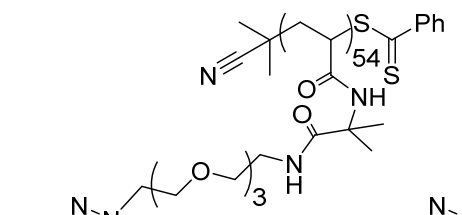<smiles>CC(C=[N+]=[N-])C1CC(C=Cc2ccccc2)CC1C</smiles>

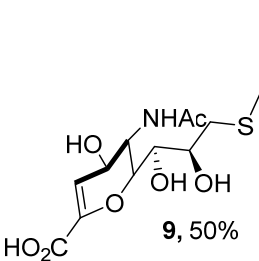<smiles>C1=CN[N+]1</smiles>

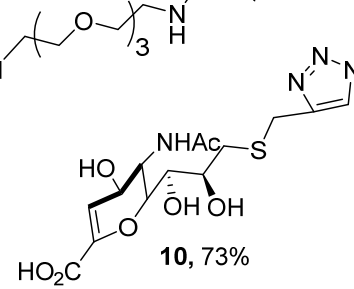

Once the chemical synthesis has been achieved, we checked that the introduction of a triazole moiety and EG linker at the C-9 position of DANA did not impair ligand-binding ability in the SA catalytic domains. The NanA-CAT was produced, purified, ${ }^{[20]}$ and co-cristallized either with DANA or compound 2, using the sitting-drop (vapor diffusion) method. Good diffraction-quality data for DANA-NanA-CAT and 2-NanA-CAT were collected and resolved at $2.7 \AA$ and $1.9 \AA$, respectively, using the previously described NanA-CAT structure from PDB entry 2 YA5 as a model for molecular replacement. ${ }^{[18]}$ Ligand 2 was shown to interact in the catalytic pocket of NanA-CAT and adopts a similar orientation in NanA-CAT as with DANA (Figure 2) or the influenza drug zanamivir. ${ }^{[18]}$ Three arginines make four strong salt bridges $(3.0 \AA)$ with the carboxylic acid oxygens of DANA, of which Arg706 forms a bifurcated interaction to orient the inhibitor in the pocket (Figure 2A). Arg332 and Arg648 each make a single salt bridge with an oxygen of the carboxylic group, symmetrically on each side of the ligand. The second face of their guanidinium groups is charge- compensated in salt bridges with Glu753 and Glu632, respectively.

The similar orientation of the DANA in DANA-NanA-CAT and 2-NanA-CAT indicates that chemical modification of C9 on the glycerol tail of DANA does not impair binding (Figure 2B). A small difference is seen between these crystal structures in that a fourth arginine, Arg351, contributes a salt bridge (3.0 $\AA$ ) with $\mathrm{O} 4$ of ligand 2 , whereas in the complex with DANA this bond remains a long-distance interaction (3.7-3.8 $\AA$ ). The other changes are situated at the exit of the pocket, where Tyr680 and Asp587 change their hydrogen bond pattern and orientation, due to the modification of 09 to a sulfur atom and linkage to the triazole group.

Molecular dynamics (MD) simulations were performed on the crystallized NanA-CAT complex with monovalent 2' (2 with one PEG linker instead of four, Figure S25) and on docking results of monovalent 2' to NanA-CBM (Figure 3). 


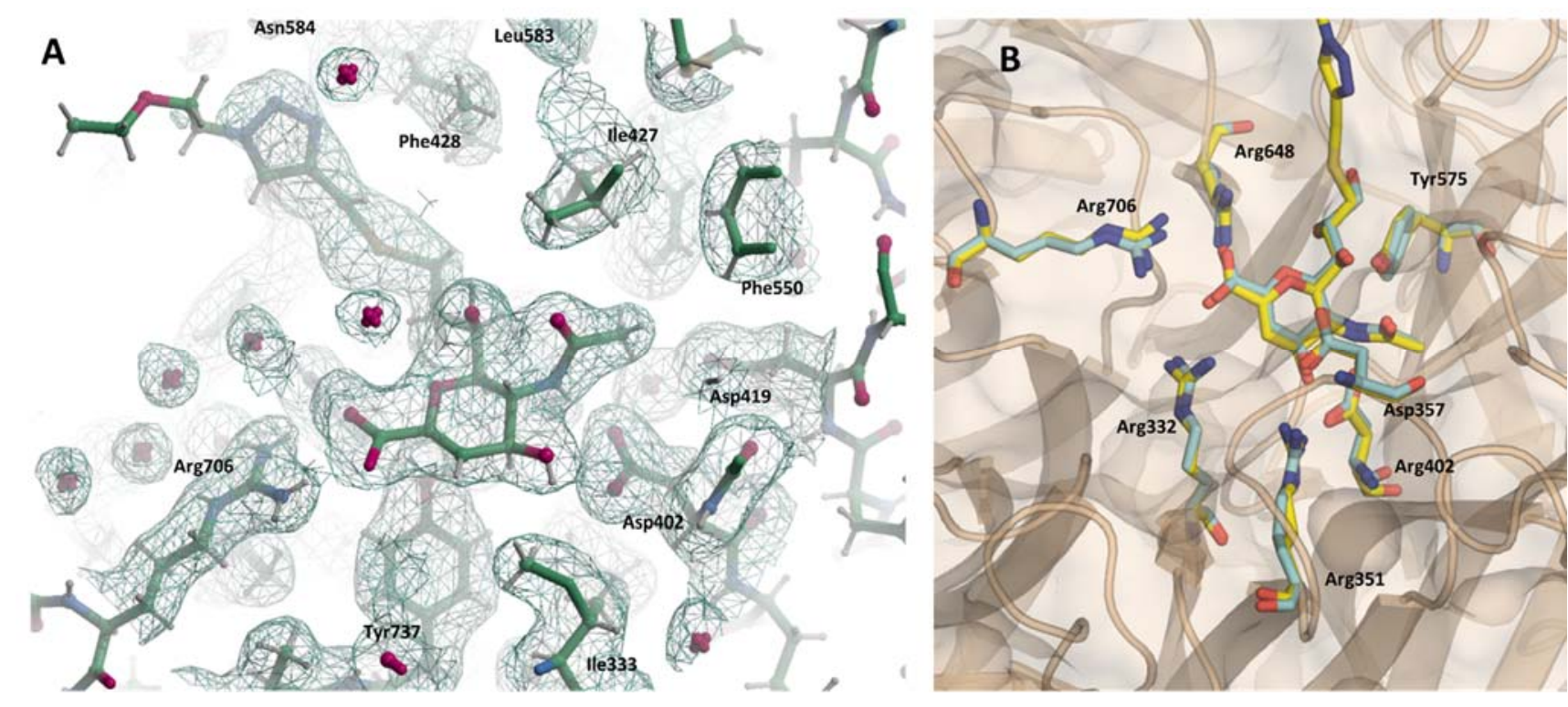

Figure 2. Binding of monovalent 2 in NanA-CAT. (A) Electron density of 2 in the binding site of the catalytic domain of NanA-CAT (PDB entry code: 7A5X). (B) Superposition, using secondary structure matching (SSM) ${ }^{[3]}$ of monovalent 2 (yellow) and DANA (blue) bound in the NanA-CAT binding site showing a similar orientation of the functional groups and amino-acid ligands in the catalytic site. The figures have been prepared $(A)$ using COOT ${ }^{[44]}$ and $(B)$ PyMOL (The PyMOL Molecular Graphics System, Version 1.2r3pre, Schrödinger, LLC.)

To estimate the relative binding preferences of 2' for the two protein domains, we used two quantities: $N_{\text {end }}$, which represents the number of simulations (out of four $=N_{\text {tot }}$ ) in which the compound remains bound at the end of the $30 \mathrm{~ns}$ simulations and $T$, which represents the time percentage of the simulations in which the ligand is found in the active site.
Compound 2' binds almost exclusively to the NanA-CAT domain $\left(N_{\text {end }} / N_{\text {tot }}=4 / 4\right.$ and $\left.T=100 \%\right)$ and in contrast to the NanA-CBM simulations $\left(N_{\text {end }} / N_{\text {tot }}=0 / 4\right.$ and $\left.T=0.02 \%\right)$ does not leave the binding site.
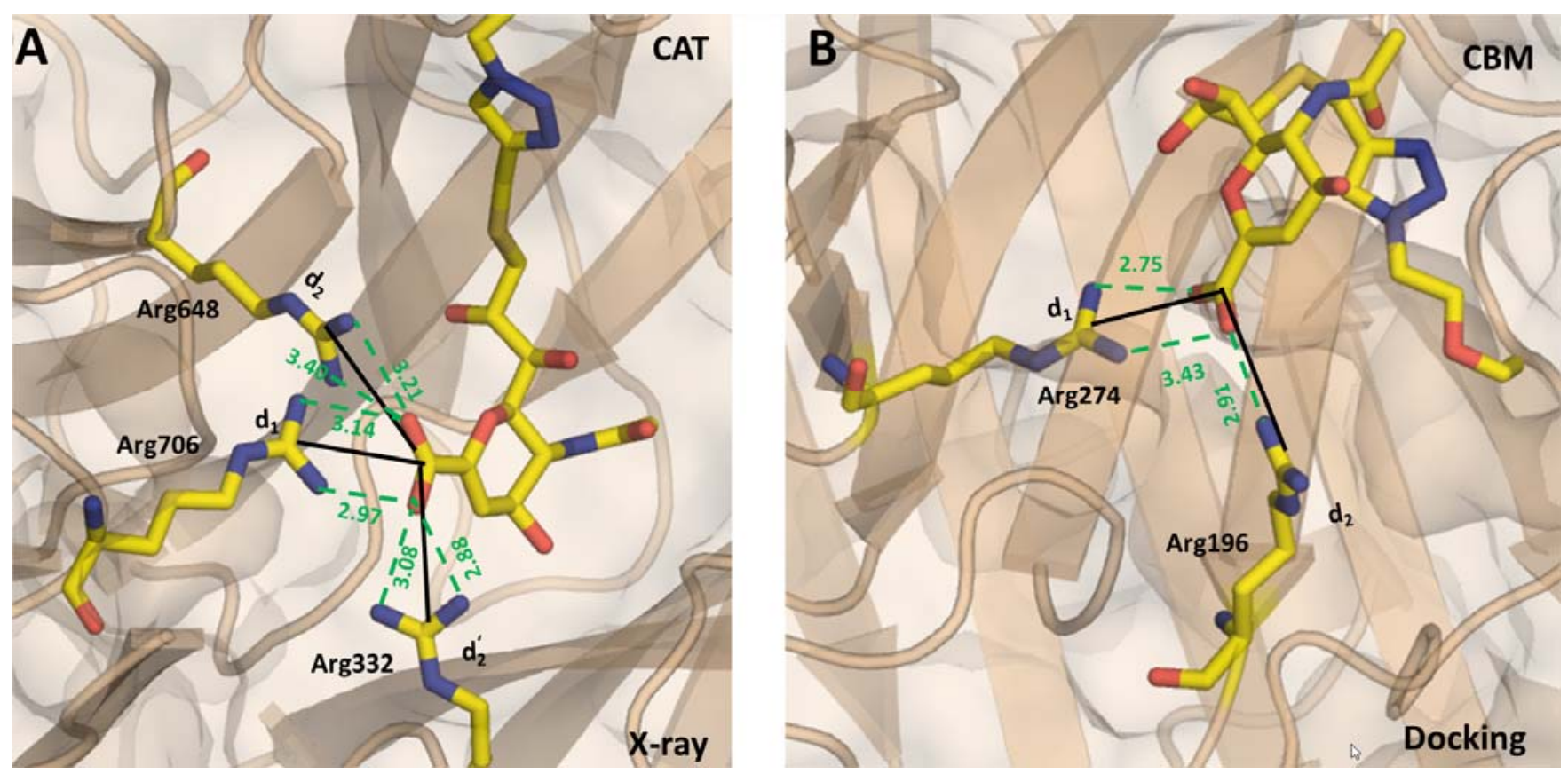

Figure 3. Binding criteria used in the MD simulations. Compound 2' was defined as bound when salt bridges with binding site arginine residues were kept. To measure that in the (A) NanA-CAT the distance with Arg706 (d1) had to be kept below $6 \AA$ and in addition at least one of the two other saltbridges d2 and d'2) had to be below $6 \AA$ at the same time; and B) for NanA-CBM two distances (d1 and d2) had to concurrently be below $6 \AA$. The distance d1/d2/d' 2 is defined as between the carbon atom of the guanidinium arginine sidechain group of corresponding residues and the carbon atom of the $\mathrm{C} 2$ positioned carboxylate group of the sugar moiety of compound 2'. The saltbridge length are shown in green and given in $\AA$.

As the specific binding of 2 in the SA catalytic domain is established, the inhibitory capacity of compounds 1-10 was assessed against NanA-CAT, NanA and BtSA. The full procedure to produce and purify these recombinant proteins (whole or truncated) fused with an affinity tag is described in the supplementary material. The inhibitory activity of compounds 1-10 was studied with the substrate 2'-(4methylumbelliferyl)- $\alpha-D-N$-acetylneuraminic acid (4-MU- 
NANA), releasing the fluorescent 4-methylumbelliferone ( $\lambda \mathrm{ex}=$ $360 \mathrm{~nm}$ and $\lambda$ em $=455 \mathrm{~nm}$ ) after enzymatic sialic acid hydrolysis. Molecular concentration values required to inhibit $50 \%$ of the enzymatic activity of NanA-CAT, NanA and BtSA measured in moles of molecules $\left(\mathrm{IC}_{50}{ }^{\mathrm{Mol}}\right)$ are listed in Table 1. As polymers 8-10 possess a large average number of DANA ligands (54 or 115 ), their $I_{50}{ }^{\mathrm{Mol}}$ value may be considered to give an inflated inhibitory potency result. We therefore also expressed the inhibitory capacity of polymers 8-10 in mol of DANA (valency-corrected $\mathrm{IC}_{50}{ }^{\mathrm{Mol}} \times \mathrm{V}=\mathrm{IC}_{50} \mathrm{Vc}^{\mathrm{Vc}}$ ) instead of molecules. Monovalent compound 2 was used as a relevant reference to calculate potential synergistic inhibitory effect due to multivalency. The enhancement factor for each clustered DANA is provided here by the valency-corrected relative inhibitory potency $\left(\mathrm{RIP}^{\mathrm{Vc}}=\mathrm{IC}_{50}(\mathbf{2}) / \mathrm{V} \times \mathrm{IC}_{50} \mathrm{Mol}\right)$.

Monovalent DANA 2 showed significantly lower $\mathrm{IC}_{50}$ values (310 fold) for NanA, NanA-CAT and BtSA compared with the ones measured for thiosialoside $\mathbf{1}$, (either measured in this study, Table 1 or previously reported). ${ }^{[20]}$ These results are in accordance with previously observed micromolar $I_{50}$ of DANA towards NanA, ${ }^{[45]}$ and confirm the superiority of this transitionstate inhibitor compared with sialoside substrate analogues. Compared with 2, divalent DANA 4 and $\mathbf{5}$ showed only a moderately improved inhibitory capacity for NanA and NanACAT but a strong multivalent effect was observed on BtSA. Compound 5 is a strong inhibitor $\left(\mathrm{IC}_{50}=46 \mathrm{nM}\right)$ for this enzyme also showing high selectivity towards $\operatorname{NanA}\left(\mathrm{IC}_{50}=44 \mu \mathrm{M}\right)$. Each of the two DANA groups of $\mathbf{5}$ are about 900 -fold more potent than the monovalent reference 2 . Further increasing the DANA valency with hexavalent CD 7 led to significantly higher inhibitory potency for $\mathrm{NanA}\left(\mathrm{IC}_{50}=0.29 \mu \mathrm{M}, \mathrm{RIP}^{\mathrm{V}_{\mathrm{c}}}=59\right)$ and very strong inhibition of $\mathrm{BtSA}\left(\mathrm{IC}_{50}=2.4 \mathrm{nM}, \mathrm{RIP}^{\mathrm{Vc}}=5763\right)$. When the divalent and $C D$ scaffolds are decorated with thiosialosides (cpds 3 and $\mathbf{6}$ ), much less potent analogues were obtained with $\mathrm{IC}_{50}$ : in the micromolar range at best.

Table 1. Inhibitory activity of compounds 1-10. Molecular and valency-corrected inhibitory concentration values $\left(\mathrm{IC}_{50 i^{\mathrm{Mol}}}\right.$ and $\mathrm{IC}_{50 \mathrm{i}}{ }^{\mathrm{Vc}}$, respectively) are given in micromolar units for new compounds $2,4-10$ and previously reported compounds $1^{[20]}$ and $3^{[20]}$. The valency-corrected relative inhibitory potencies (RIPVC) showed the enhancement factor of each clustered DANA compared with 2.

\begin{tabular}{|c|c|c|c|c|c|c|c|}
\hline \multirow{2}{*}{$\frac{\text { Cpds }}{\text { Cpds }}$} & \multicolumn{3}{|c|}{ NanA } & \multicolumn{2}{|l|}{ NanA-CAT } & \multicolumn{2}{|l|}{ BtSA } \\
\hline & Valency & $\mathrm{IC}_{50 \mathrm{i}}^{\mathrm{Mol}}\left(\mathrm{IC}_{50 \mathrm{i}} \mathrm{i}^{\mathrm{Vc}}\right)$ & RIPVC & $\mathrm{IC}_{50 \mathrm{i}}\left(\mathrm{IC}_{50 \mathrm{i}} \mathrm{V}^{\mathrm{Vc}}\right)$ & RIPVC & $\mathrm{IC}_{50 \mathrm{i}}(\mu \mathrm{M})$ & $\mathrm{RIPi} \mathrm{VC}$ \\
\hline & 1 & $1042 \pm 20^{[a]}$ & 0.1 & $426 \pm 53$ & 0.2 & $271 \pm 9$ & 0.3 \\
\hline & 1 & $103 \pm 5$ & 1 & $97 \pm 11$ & 1 & $83 \pm 11$ & 1 \\
\hline & 2 & $206 \pm 23^{[a]}$ & 0.25 & $258 \pm 2$ & 0.2 & $>1000$ & $<0.1$ \\
\hline & 2 & $5 \pm 1$ & 10 & $77 \pm 7$ & 0.6 & $0.81 \pm 0.04$ & 51 \\
\hline & 2 & $44 \pm 5$ & 1 & $39 \pm 2$ & 1.2 & $0.046 \pm 0.002$ & 902 \\
\hline & 6 & $>1000$ & $<0.1$ & $921 \pm 53$ & 0.05 & $1.3 \pm 0.2$ & 11 \\
\hline & 6 & $0.29 \pm 0.02$ & 59 & $2 \pm 0.2$ & 8 & $0.0024 \pm 0.0002$ & 5763 \\
\hline & 54 & $\begin{array}{l}>20 \\
(>1000)\end{array}$ & $<0.1$ & $\begin{array}{l}0.199 \pm 0.052 \\
(8 \pm 2)\end{array}$ & 12 & $\begin{array}{l}6 \pm 1 \\
(327 \pm 1)\end{array}$ & $<0.3$ \\
\hline & 54 & $\begin{array}{l}0.00014 \pm 8.10^{-8} \\
\left(0.0077 \pm 4.10^{-7}\right)\end{array}$ & 13376 & $\begin{array}{l}0.00055 \pm 3.10^{-8} \\
\left(0.030 \pm 2.10^{-6}\right)\end{array}$ & 3222 & $\begin{array}{l}0.00048 \pm 1.10^{-8} \\
\left(0.026 \pm 7.10^{-7}\right)\end{array}$ & 3192 \\
\hline & 115 & $\begin{array}{l}0.000032 \pm 9.10^{-9} \\
\left(0.0037 \pm 1.10^{-7}\right)\end{array}$ & 27837 & $\begin{array}{l}0.000690 \pm 8.10^{-8} \\
\left(0.078 \pm 10.10^{-6}\right)\end{array}$ & 1243 & $\begin{array}{l}0.000067 \pm 2.10^{-9} \\
\left(0.0077 \pm 2.10^{-7}\right)\end{array}$ & 10779 \\
\hline
\end{tabular}

[a] Values previously described values in ref [20]

The flexible and rigid DANA polymers $\mathbf{9}$ and $\mathbf{1 0}$ proved highly potent with unprecedented levels of inhibitory capacity for the targets. The polymers reached picomolar and low nanomolar levels in the inhibition for NanA, NanA-CAT when expressed in moles of molecules or DANA groups, respectively. NanA-CAT was more potently inhibited by the flexible poly-DANA $9\left(\mathrm{IC}_{50} \mathrm{Mol}\right.$ $=550 \mathrm{pM}, \mathrm{IC}_{50}{ }^{\mathrm{Vc}}=30 \mathrm{nM}$ ) while lower inhibitory values were obtained with poly-DANA 10 and NanA $\left(\mathrm{IC}_{50} \mathrm{Mol}=32 \mathrm{pM}, \mathrm{IC}_{50} \mathrm{Vc}^{\mathrm{Vc}}\right.$ $=3.7 \mathrm{nM})$ or BtSA $\left(\mathrm{IC}_{50}{ }^{\mathrm{Mol}}=67 \mathrm{pM}, \mathrm{IC}_{50}{ }^{\mathrm{Vc}}=7.7 \mathrm{nM}\right)$. For these two polymers, each DANA ligand surpassed the inhibitory capacity of the monovalent reference 2 by three (RIPVc 10 $\mathrm{BtSA}=1243$, Table 1) to more than four orders of magnitudes
$\left(R^{\prime} P^{V c} 10-N a n A=27837\right)$. We also determined the inhibitory constants $\left(K_{\mathrm{i}}\right)$ and valency-corrected inhibitory constants $\left(K_{\mathrm{i}}^{\mathrm{Vc}}\right)$ for the DANA ligands attached to the two best inhibitors for NanA and BtSA (9, 10 and 7, 10, respectively). As the compounds are highly potent inhibitors, DANA concentration used during the assay was not significantly higher than [SA] and we had to apply the Morrison equation for tight-binding inhibitors. ${ }^{[46,47]}$ Indeed, equations of the Henri-MichaelisMenten type are only valid if the enzyme concentration is much lower than the inhibitor concentration. We also assumed a competitive binding mode for the multivalent DANA as suggested from crystallography and MD simulations showing 
DANA interaction in the catalytic binding pocket. The low $K_{\mathrm{i}}^{\mathrm{Vc}}$ values measured for the best inhibitors $9\left(K_{\mathrm{i}}^{\mathrm{Vc}}=17.4 \pm 1.7 \mathrm{nM}\right)$ and $10\left(K_{\mathrm{i}}^{\mathrm{Vc}}=16.2 \pm 1.9 \mathrm{nM}\right)$ for NanA and, $7\left(K_{\mathrm{i}}=0.56 \pm 0.23\right.$ $\mathrm{nM})$ and $10\left(K_{\mathrm{i}}^{\mathrm{Vc}}=10.7 \pm 1.6 \mathrm{nM}\right)$ for BtSA, confirmed the strong potency and synergistic effects offered by these multivalent-DANA.

Next, we evaluated whether the strong inhibition of the enzymatic activity provided by the multivalent DANA was correlated with a strong binding affinity for the targets. More precisely, we assessed whether the compounds could efficiently prevent NanA and NanA-CAT binding to a labelled multi-sialylated protein mimicking natural sialyl glycans at cell surfaces. BtSA was not evaluated in this assay due to its much lower binding affinity for the labelled protein. NanA constructs were coated onto a microplate surface and labelled bovine serum albumin (BSA) was coated with non-hydrolysable thiosialosides. ${ }^{[20]}$ This system, adapted from "lectin profiling" technology, allowed determination of the half maximal inhibitory concentrations of binding values $\mathrm{ICb}_{50}$ and to calculate the valency-corrected relative inhibitory potency of binding RIPbVC (Table 2).

The DANA derivatives showed $\mathrm{ICb}_{50} \mathrm{Mol}$ one to two-order of magnitude lower against NanA-CAT than against NanA, meaning that the compounds are more efficient in blocking the catalytic site alone compared to the full-length enzyme bearing the CBM (sialoside-binding domain). NanA-CBM display a higher intrinsic affinity for sialylated surfaces than do NanA$\mathrm{CAT}^{[20]}$ and the lower binding capacity of the compounds for NanA compared with NanA-CAT, suggest that the DANA ligands interact in the CAT domain only, as observed in our structural and simulation data.

The binding inhibition potential observed with compounds 1-10 shows significant homologies with their inhibitory capacity (except for $\mathbf{7}$ on NanA) because (i) the DANA derivatives are significantly more potent than their sialoside derivatives, (ii) the low-valency compounds 2-7 show a moderate level of synergistic effects, if any, and (iii) the DANA polymers $\mathbf{9 - 1 0}$ are highly potent inhibitors of NanA binding. These compounds displayed picomolar $\mathrm{ICb}_{50} \mathrm{Mol}$ and low nanomolar $\mathrm{ICb}_{50} \mathrm{Vc}^{\mathrm{V}}$ inhibition level. 10 was the most potent polymer with $\mathrm{ICb}_{50} \mathrm{Mol}=$ $31 \mathrm{pM}$ and $\mathrm{ICb}_{50}{ }^{\mathrm{vc}=} 3.6 \mathrm{nM}$ for NanA-CAT. 9-10 also display outstanding multivalent effects for NanA with RIPvc values of 17242 and 38461 (Table 2), respectively. Thus, the DANA polymers combine an outstanding potential for blocking the enzymatic hydrolysis activities and binding capacities of NanA. Both effects are also observed on the truncated domain NanACAT, showing that DANA binding occurs at catalytic domains as suggested by $\mathrm{X}$-ray structural data and molecular dynamic simulations (Figures 2, 3).

Dynamic light scattering (DLS) experiments were performed by means of titration to polymer 10, carrying 115 DANA molecules. DLS analysis showed that upon titration of the sialidase proteins to polymer 10 , the hydrodynamic radius $\left(R_{h}\right)$ for the protein peak doubles in size for those BtSA and NanA proteins (Figures S17-S24). Thus, the multivalent DANA 10 has the potency to cluster SA catalytic domains in a similar fashion to that previously reported between GalNAc binding lectins and a submaxillary mucin polymer bearing $\sim 2300 \alpha-$ GalNAc residues. The lectins displayed a much higher affinity for the polymeric GalNAc, explained by a reduced off-rate of the complex due to a lectin diffusion mechanism along the
GalNAc chain. ${ }^{[48]}$ The high synergistic effects observed here with multivalents $\mathbf{9}$ and $\mathbf{1 0}$ are likely due to a similar "bind and jump" mechanism where the catalytic domain diffuses from one DANA ligand to another.

\section{Conclusion}

In conclusion, we developed polymers of the sialyl cation transition-state analogue DANA with unprecedented level of inhibition for a bacterial SA of the GH 33 family. The DANA clusters provided valency-corrected multivalent effects exceeding four orders of magnitude on NanA or BtSA. As far as we know, such a level of synergistic inhibition has never been achieved with previously described multivalent enzyme inhibitors. The improved inhibition and affinity being also observed on the truncated catalytic domain NanA-CAT alone, we forecast that this strategy may also be successful in blocking other classes of biologically relevant bacterial, viral or human SA lacking a CBM domain.

Table 2. Binding inhibition of compounds 1-10 in $\mu \mathrm{M}$

\begin{tabular}{|c|c|c|c|c|c|}
\hline \multicolumn{5}{|c|}{ NanA } & NanA-CAT \\
\hline Cpds & Val & $\begin{array}{l}\mathrm{ICb}_{50} \mathrm{Mol}^{\mathrm{Mol}} \\
\left(\mathrm{ICb}_{50}{ }^{\mathrm{Vc}}\right)\end{array}$ & $\mathrm{RIPb}^{\mathrm{VC}}$ & $\begin{array}{l}\mathrm{IC}_{\mathrm{b} 50} \mathrm{Mol} \\
\left(\mathrm{ICb}_{50}{ }^{\mathrm{Vc}}\right)\end{array}$ & $\mathrm{RIPb}^{\mathrm{VC}}$ \\
\hline & 1 & $8420 \pm 100^{[a]}$ & 0.06 & $-[-[b]$ & -- \\
\hline & 1 & $>500$ & 1 & $2.4 \pm 0.8$ & 1 \\
\hline & 2 & $880 \pm 200^{[a]}$ & $<0.28$ & $-[-[b]$ & -- \\
\hline & 2 & $160 \pm 20$ & $>1.5$ & $0.40 \pm 0.05$ & 3 \\
\hline & 2 & $310 \pm 50$ & $>0.8$ & $0.20 \pm 0.02$ & 6 \\
\hline & 6 & $60 \pm 5$ & $>1.4$ & $4.5 \pm 2.0$ & 0.09 \\
\hline & 6 & $>250$ & $>0.3$ & $0.9 \pm 0.1$ & 0.4 \\
\hline & 54 & $\begin{array}{l}0.055 \\
(3.0 \pm 1.5)\end{array}$ & $>166$ & $\begin{array}{l}0.014 \\
(0.8 \pm 0.1)\end{array}$ & 3 \\
\hline 9 & 54 & $\begin{array}{l}0.00054 \\
(0.029 \pm 0.004)\end{array}$ & $>17242$ & $\begin{array}{l}0.000068 \\
(0.0037 \pm 0.0013)\end{array}$ & 648 \\
\hline & 115 & $\begin{array}{l}0.00011 \\
(0.013 \pm 0.002)\end{array}$ & $>38461$ & $\begin{array}{l}0.000031 \\
(0.0036 \pm 0.0012)\end{array}$ & 667 \\
\hline
\end{tabular}

\section{Acknowledgements}

This work was carried out with financial support from the Centre National de la Recherche Scientifique (CNRS), the Ministère de l'Enseignement Supérieur et de la Recherche in France and the National Agency for Research (ANR project HICARE 17-CE07-028-01). We acknowledge SOLEIL for providing synchrotron radiation facilities and would like to thank Leonard Chavas for his assistance in using beamline Proxima1.

Keywords: Sialidases • Multivalency • Inhibitors • Enzymes • 
[1] T. Guo, R. Héon-Roberts, C. Zou, R. Zheng, A. V. Pshezhetsky, C. W. Cairo, J. Med. Chem. 2018, 61, 1126111279.

[2] W. Li, A. Santra, H. Yu, T. J. Slack, M. M. Muthana, D. Shi, Y. Liu, X. Chen, J. Org. Chem. 2019, 84, 6697-6708.

[3] Hinou Hiroshi, Miyoshi Risho, Takasu Yasuaki, Kai Hirokazu, Kurogochi Masaki, Arioka Shingo, Gao XiaoDong, Miura Nobuaki, Fujitani Naoki, Omoto Shinya, Yoshinaga Tomokazu, Fujiwara Tamio, Noshi Takeshi, Togame Hiroko, Takemoto Hiroshi, Nishimura Shin-Ichiro, Chem. - Asian J. 2011, 6, 1048-1056.

[4] T. Guo, P. Dätwyler, E. Demina, M. R. Richards, P. Ge, C. Zou, R. Zheng, A. Fougerat, A. V. Pshezhetsky, B. Ernst, C. W. Cairo, J. Med. Chem. 2018, 61, 1990-2008.

[5] C. W. Cairo, MedChemComm 2014, 5, 1067-1074.

[6] A. Albohy, Y. Zhang, V. Smutova, A. V. Pshezhetsky, C. W. Cairo, ACS Med. Chem. Lett. 2013, 4, 532-537.

[7] C. D. Hunter, N. Khanna, M. R. Richards, R. Rezaei Darestani, C. Zou, J. S. Klassen, C. W. Cairo, ACS Chem. Biol. 2018, 13, 922-932.

[8] S. Magesh, S. Moriya, T. Suzuki, T. Miyagi, H. Ishida, M. Kiso, Bioorg. Med. Chem. Lett. 2008, 18, 532-537.

[9] T. J. Slack, W. Li, D. Shi, J. B. McArthur, G. Zhao, Y. Li, A. Xiao, Z. Khedri, H. Yu, Y. Liu, X. Chen, Bioorg. Med. Chem. 2018, 26, 5751-5757.

[10] P. Kiran, S. Bhatia, D. Lauster, S. Aleksić, C. Fleck, N. Peric, W. Maison, S. Liese, B. G. Keller, A. Herrmann, R. Haag, Chem. - Eur. J. 2018, 24, 19373-19385.

[11] S. Spjut, W. Qian, J. Bauer, R. Storm, L. Frängsmyr, T. Stehle, N. Arnberg, M. Elofsson, Angew. Chem. Int. Ed. 2011, 50, 6519-6521.

[12] R. Caraballo, M. Saleeb, J. Bauer, A. M. Liaci, N. Chandra, R. J. Storm, L. Frängsmyr, W. Qian, T. Stehle, N. Arnberg, M. Elofsson, Org. Biomol. Chem. 2015, 13, 9194-9205.

[13] D. Lauster, S. Klenk, K. Ludwig, S. Nojoumi, S. Behren, L. Adam, M. Stadtmüller, S. Saenger, S. Zimmler, K. Hönzke, L. Yao, U. Hoffmann, M. Bardua, A. Hamann, M. Witzenrath, L. E. Sander, T. Wolff, A. C. Hocke, S. Hippenstiel, S. De Carlo, J. Neudecker, K. Osterrieder, N. Budisa, R. R. Netz, C. Böttcher, S. Liese, A. Herrmann, C. P. R. Hackenberger, Nat. Nanotechnol. 2020, DOI 10.1038/s41565-020-0660-2.

[14] M. Mammen, G. Dahmann, G. M. Whitesides, J. Med. Chem. 1995, 38, 4179-4190.

[15] L. Fu, Y. Bi, Y. Wu, S. Zhang, J. Qi, Y. Li, X. Lu, Z. Zhang, X. Lv, J. Yan, G. F. Gao, X. Li, J. Med. Chem. 2016, 59, 6303-6312.

[16] A. K. Weight, J. Haldar, L. Álvarez de Cienfuegos, L. V. Gubareva, T. M. Tumpey, J. Chen, A. M. Klibanov, J. Pharm. Sci. 2011, 100, 831-835.

[17] T. Honda, S. Yoshida, M. Arai, T. Masuda, M. Yamashita, Bioorg. Med. Chem. Lett. 2002, 12, 1929-1932.

[18] H. Gut, G. Xu, G. L. Taylor, M. A. Walsh, J. Mol. Biol. 2011, 409, 496-503.

[19] S. Thobhani, B. Ember, A. Siriwardena, G.-J. Boons, J. Am. Chem. Soc. 2003, 125, 7154-7155.

[20] Y. Brissonnet, C. Assailly, A. Saumonneau, J. Bouckaert, M. Maillasson, C. Petitot, B. Roubinet, B. Didak, L. Landemarre, C. Bridot, R. Blossey, D. Deniaud, X. Yan, J. Bernard, C. Tellier, C. Grandjean, F. Daligault, S. G. Gouin, Chem. - Eur. J. 2019, 25, 2358-2365.

[21] S. G. Gouin, Chem. - Eur. J. 2014, 20, 11616-11628.

[22] P. Compain, A. Bodlenner, ChemBioChem 2014, 15, 12391251.

[23] N. Kanfar, E. Bartolami, R. Zelli, A. Marra, J.-Y. Winum, S. Ulrich, P. Dumy, Org. Biomol. Chem. 2015, DOI 10.1039/C5OB01405K.

[24] C. O. Mellet, J.-F. Nierengarten, J. M. G. Fernández, J. Mater. Chem. B 2017, DOI 10.1039/C7TB00860K.
[25] K.-H. Park, M.-G. Kim, H.-J. Ahn, D.-H. Lee, J.-H. Kim, Y.-W. Kim, E.-J. Woo, Biochim. Biophys. Acta BBA Proteins Proteomics 2013, 1834, 1510-1519.

[26] D. Parker, G. Soong, P. Planet, J. Brower, A. J. Ratner, A. Prince, Infect. Immun. 2009, 77, 3722-3730.

[27] M. von Itzstein, W.-Y. Wu, G. B. Kok, M. S. Pegg, J. C. Dyason, B. Jin, T. Van Phan, M. L. Smythe, H. F. White, S. W. Oliver, P. M. Colman, J. N. Varghese, D. M. Ryan, J. M. Woods, R. C. Bethell, V. J. Hotham, J. M. Cameron, C. R. Penn, Nature 1993, 363, 418-423.

[28] V. Wittmann, R. J. Pieters, Chem. Soc. Rev. 2013, 42, 44924503.

[29] J. Bouckaert, Z. Li, C. Xavier, M. Almant, V. Caveliers, T. Lahoutte, S. D. Weeks, J. Kovensky, S. G. Gouin, Chem. Eur. J. 2013, 19, 7847-7855.

[30] C. Decroocq, D. Rodríguez-Lucena, V. Russo, T. Mena Barragán, C. Ortiz Mellet, P. Compain, Chem. - Eur. J. 2011, 17, 13825-13831.

[31] V. Lehot, Y. Brissonnet, C. Dussouy, S. Brument, A. Cabanettes, E. Gillon, D. Deniaud, A. Varrot, P. Le Pape, S. G. Gouin, Chem. - Eur. J. 2018, 24, 19243-19249.

[32] C. R. Becer, M. I. Gibson, J. Geng, R. Ilyas, R. Wallis, D. A. Mitchell, D. M. Haddleton, J. Am. Chem. Soc. 2012, 132, 15130-15132.

[33] S. Brument, C. Cheneau, Y. Brissonnet, D. Deniaud, F. Halary, S. G. Gouin, Org. Biomol. Chem. 2017, 15, 7660 7671.

[34] Y.-S. Hsiao, D. Parker, A. J. Ratner, A. Prince, L. Tong, Biochem. Biophys. Res. Commun. 2009, 380, 467-471.

[35] R. Kuhn, P. Lutz, D. L. Macdonald, Chem. Ber. 1966, 99, 611-617.

[36] S. Wolf, S. Warnecke, J. Ehrit, F. Freiberger, R. GerardySchahn, C. Meier, ChemBioChem n.d., 13, 2605-2615.

[37] T. G. Warner, Biochem. Biophys. Res. Commun. 1987, 148, 1323-1329.

[38] M. E. Levere, H. T. Ho, S. Pascual, L. Fontaine, Polym. Chem. 2011, 2, 2878-2887.

[39] S. Pascual, T. Blin, P. J. Saikia, M. Thomas, P. Gosselin, L. Fontaine, J. Polym. Sci. Part Polym. Chem. 2010, 48, 50535062.

[40] V. Lapinte, J.-C. Brosse, L. Fontaine, Macromol. Chem. Phys. 2004, 205, 824-833.

[41] V. Lapinte, L. Fontaine, V. Montembault, I. Campistron, D. Reyx, J. Mol. Catal. Chem. 2002, 190, 117-129.

[42] N. A. Rodios, J. Heterocycl. Chem. 1984, 21, 1169-1173.

[43] E. Krissinel, K. Henrick, Acta Crystallogr. D Biol. Crystallogr. 2004, 60, 2256-2268.

[44] P. Emsley, K. Cowtan, Acta Crystallogr. D Biol. Crystallogr. 2004, 60, 2126-2132.

[45] Z. Xu, S. von Grafenstein, E. Walther, J. E. Fuchs, K. R. Liedl, A. Sauerbrei, M. Schmidtke, Sci. Rep. 2016, 6, DOI 10.1038/srep25169.

[46] D. J. Murphy, Anal. Biochem. 2004, 327, 61-67.

[47] R. A. Copeland, Enzymes, John Wiley \& Sons, Inc., New York, USA, 2000.

[48] T. K. Dam, T. A. Gerken, B. S. Cavada, K. S. Nascimento, T. R. Moura, C. F. Brewer, J. Biol. Chem. 2007, 282, 28256-28263 
